\title{
Liberalismo, ciudadanía y vecindad en Nueva Granada (Colombia) durante la primera mitad del siglo XIX ${ }^{\left.12^{*}\right)}$
}

\author{
Roicer Flórez Bolivar
}

Sergio Paolo Solano D.

Jairo Álvarez Jiménez $z^{3(*)}$

El artículo analiza el imaginario político-social y la cultura política que se impuso en Nueva Granada durante la primera mitad del siglo XIX. Los autores sostienen que al ser resultado de la combinación de prácticas políticas del Antiguo Régimen y la del nuevo ordenamiento jurídico liberal, durante este periodo la participación de los ciudadanos en los asuntos públicos se hacía dentro de un orden corporativo y jerárquico como consecuencia de que la comunidad seguía anclada en un orden y en un imaginario tradicional. De esta manera, la comunidad era un importante mecanismo de regulación de los comportamientos sociales.

Palabras claves: Nueva Granada, liberalismo, ciudadanía, vecindad, cultura política.

\footnotetext{
${ }^{1}$ Artigo recebido em 5/5/2011 e aprovado em 15/11/2011.

${ }^{2(*)}$ Este artículo es resultado de los proyectos de investigaciones Historia social, cultural y política del Bolívar Grande (Colombia) durante el siglo XIX; Trabajo, estilos de vida política y conflictos sociales en el Caribe Colombiano, 1850-1930, y Guerras civiles, iglesia y política en el Caribe colombiano durante el siglo XIX. Agradecemos las sugerencias hechas por los evaluadores anónimos que permitieron mejorar el artículo.

${ }^{\left.3{ }^{* *}\right)}$ Profesores del Programa de Historia, Facultad de Ciencias Humanas, Universidad de Cartagena de Indias (Colombia). Miembros del grupo de investigaciones Frontera, Sociedad y Cultura del Caribe y Latinoamérica.rflorezb@unicartagena.edu.co; ssolanod@unicartagena.edu.co; jalvarezj@ unicartagena.edu.co
} 


\section{Liberalismo, cidadania e vizinhança em Nova Granada (Colômbia) durante a primeira metade do século XIX}

O artigo analisa o imaginário politico-social e a cultura politica que foi imposta na Nova Granada durante a primeira metade do século XIX. Os autores apoiam que sendo o resultado da combinação de práticas politicas do Antigo Regime e da nova ordem juridica liberal, durante este periodo a participação dos cidadãos nos negócios públicos era feita numa ordem corporativa e hierárquica, após do fato de que a comunidade ainda ficava ancorada numa ordem e num imaginário tradicional. Desta maneira, a comunidade é entendida como um importante mecanismo de regulação dos comportamentos sociais. Palavras-chave: Nova Granada, o liberalismo, a cidadania, residência, cultura política.

\section{Liberalism, citizenship and surroundings in New Granada (Colombia) during the first half of the nineteenth century}

The article analyzes the political and social imagination and political culture that prevailed in New Granada during the first half of the nineteenth century. The authors argue that to be the result of the combination of political practices of the Old Regime and the new liberal legal system during this period, the participation of citizens in public affairs was done within a corporate and hierarchical order as a result of the community was founded on an imaginary and traditional order. Thus, the community was an important mechanism for regulating social behavior.

Key words: New Granada, liberalism, citizenship, residence, political culture.

\section{Libéralisme, citoyenneté et promiscuité en Nouvelle-Grenade (Colombie) pendant la première moitié du XIXème siècle}

Larticle analyse l'imaginaire politico-social et la culture politique imposée en NouvelleGrenade pendant la première moitié du XIXème siècle. Les auteurs soutiennent l'idée suivante: découlant de la combinaison entre les pratiques politiques de l'Ancien Régime et le nouvel ordre juridique libéral, la participation des citoyens aux affaires publiques, pendant cette période, s'inscrivait dans un ordre corporatiste et hiérarchique, car la communauté était encore ancrée dans un ordre et un imaginaire traditionnel. La communauté est ainsi envisagée comme un important mécanisme de régulation des comportements sociaux.

Mots-clés: Nouvelle-Grenade, libéralisme, citoyenneté, résidence, culture politique. 


\section{Presentación}

Situado en el cruce de caminos de los temas de las independencias, la soberanía, la nación y el Estado moderno, el estudio de los procesos que llevaron al establecimiento de la ciudadanía en Latinoamérica durante el siglo XIX ha adquirido cierto grado de complejidad hasta tal punto que todos los aspectos que le competen están sometidos a discusiones. En términos generales, podemos resumir los puntos de discusión en los siguientes aspectos: 1) la geohistórica de la modernidad, sus actores, especificidades y las formas que esta asumió;4 2) la crisis de las monarquías iberoamericanas y los procesos de independencias; 5 3) las relaciones entre modernidad y liberalismo, y las características de este en Hispanoamericana;6 4) las transformaciones sufridas por el principio de

\footnotetext{
${ }^{4}$ Frente a la idea que hizo del Atlántico Norte el espacio natural de las revoluciones burguesas, la historiografía política reciente ha construido el concepto de las revoluciones en el mundo Atlántico, lo que ha permitido integrar el área iberoamericana, usualmente dejada a un lado por considerarse "atípica”. Un análisis genealógico de esta tesis en J. Alberto Navas, "La 'Revolución Atlántica' y las independencias americanas. Una polémica historiográfica inconclusa”, Takwá vol. 8, No. 14, Guadalajara, Universidad de Guadalajara, 2008, p. 138-156; José A. Piqueras, "Revolución en ambos hemisferios: común, diversa(s), confrontada(s)”, Historia Mexicana vol. LVIII, No. 1, México, El Colegio de México, 2008, p. 31-98; María T. Calderón y Clément Thibaud, La majestad de los pueblos en la Nueva Granada y Venezuela 1780-1832, Bogotá, Universidad Externado de ColombiaIFEA-Taurus, 2010, p. 23-40; Antonio Annino, "Imperio, constitución y diversidad en la América Hispana”, Historia Mexicana vol. LVIII, No. 1, México, El Colegio de México, 2008, p. 179-227.

${ }^{5}$ Alfredo Ávila, "las revoluciones hispanoamericanas vistas desde el siglo XXI", Revista de Historia Iberoamericana vol. 1, No. 1, Madrid, Universia, 2008, p. 4-34.

${ }^{6}$ Tomás Pérez, "La construcción de las naciones como problema historiográfico: el caso del mundo hispánico", Historia Mexicana vol. LIII, No. 2, México, El Colegio de México, 2003, p. 275-311; Alfredo Ávila, "De las independencias a la modernidad. Notas sobre un cambio historiográfico", Erika Pani y Alicia Salmerón (coord.), Conceptualizar lo que se ve. François-Xavier Guerra. Historiador: Homenaje, México, Instituto Mora, 2006, p. 76-112; Alfredo Ávila y Virginia Guedea, "De la independencia a los procesos autonomistas novohispanos: balance de la historiografía reciente", Manuel Chust y José Antonio Serrano (eds.), Debates sobre las independencias iberoamericanas, Madrid, AHILA- Iberoamericana-Vervuert, 2007, p. 255-276; Mirian Galante, "La revolución hispana a debate: lecturas recientes sobre la influencia del proceso gaditano en México", Revista Complutense de Historia de América vol. 33, Madrid, Universidad Complutense, 2007, p. 93-112.
} 
la soberanía,7 5) la construcción de la esfera de la opinión pública, ${ }^{8}$ y 6) las construcciones de las ciudadanías. ${ }^{9}$

Fue François-Xavier Guerra uno de los primeros en construir un modelo que articuló los aspectos enunciados, y que supuso el choque y/o cruces entre las tradiciones políticas del Antiguo Régimen y las peculiaridades adquiridas por la modernidad bajo la monarquía hispanoamericana durante el corto lapso de tiempo que va de 1808 a 1821. A partir de la propuesta de F-X. Guerra se suscitaron varios estudios acerca del establecimiento de la ciudadanía en las nacientes repúblicas latinoamericanas, remarcando en algunos casos la novedad y en otros la simbiosis. En ambos casos, las interpretaciones poco se alejan de uno de los ejes centrales de la interpretación de Guerra: la modernidad, sus formas de sociabilidad, la ciudadanía y la opinión pública fue un proceso que se irradió desde las elites hacia los sectores medios y bajos de la población. ${ }^{10}$

Así como la obra de F-X. Guerra ha tenido seguidores entre los estudiosos de Colombia ${ }^{11}$ también ha suscitado reacciones contrarias, al cuestionársele su

\footnotetext{
${ }^{7}$ Eugenia Roldán, “'Pueblo' y 'Pueblos' en México, 1750-1850: un ensayo de historia conceptual", Araucaria vol. 9, No. 17, Sevilla, Universidad de Sevilla, 2007, p. 268-288; Mónica quijada, "Sobre 'nación', 'pueblo, 'soberanía' y otros ejes de la modernidad en el mundo hispánico", Jaime Rodríguez (coord.), Las nuevas naciones. España y México 1800-1850, Madrid, Mapfre, 2008, p. 19-51.

${ }^{8}$ François-Xavier Guerra, “'Voces del pueblo'. Redes de comunicación y orígenes de la opinión en el mundo hispánico (1808-1814)", Revista de Indias vol. LVII, No. 255, Madrid, CSIS, 2002, p. 357 384; Elías Palti, "Guerra y Habermas: ilusiones y realidad de la esfera pública latinoamericana”, E. Pani y A. Salmerón, Conceptualizar lo que se ve. François-Xavier Guerra. Historiador: Homenaje, p. 461-483; Mariana Terán, "De nación española a federación mexicana. La opinión pública en la formación de la nación”, J. Rodríguez, Las nuevas naciones. España y México 1800-1850, p. 125-143.

${ }^{9}$ Hilda Sábato, "On political citizenship in nineteenth century Latin America", The American Historical Review vol. 106, No. 4, Washington, AHA, 2001, p. 1290-1315. http://www.jstor.org/stable/2692950; Marta Irurozqui, La ciudadanía en debate en América Latina. Discusiones historiográficas y una propuesta teórica sobre el valor público de la infracción electoral, Lima, IEP, 2004; Elías Palti, "Revisión y revolución rupturas y continuidades en la historia y en la historiografía", Historia Mexicana vol. LVIII, No. 3, México, El Colegio de México, 2009, p. 1171-1198.

${ }^{10}$ François-Xavier Guerra, Modernidad e independencias, México, Mapfre-FCE, 1992; Antonio Annino, "Pueblos, liberalismo y nación en México", Antonio Annino y François-Xavier Guerra (coords.), Inventando la nación: Iberoamérica siglo XIX, México, FCE, 2003, p. 399-430; Marcello Carmagnani y Alicia Hernández, "La ciudadanía orgánica mexicana, 1850-1910”, Hilda Sábato (coord.), Ciudadanía política y formación de las naciones. Perspectivas históricas de América Latina, México, El Colegio de México-FCE, 1999, p. 371-404.

${ }^{11}$ Steinar Saether, "Independence and the redefinition of indianness around Santa Marta", Journal of Latin American Studies, vol. 37, No. 1, Cambridge, Cambridge University Press, 2005, p. 55-80; Margarita Garrido, "Nueva Granada entre el orden colonial y el republicano: lenguajes e imagina-
} 
imagen de la modernidad política solo posible de arriba hacia abajo. Para el caso de este país, Marixa Lasso ${ }^{12}$ ha planteado la idea de una modernidad alternativa construida por los sectores subalternos. Estudiosa de la cultura política de los negros libres y mulatos en la época de la Independencia de Cartagena, ha propuesto que la política entre los afrodescendientes de esta ciudad sea estudiada como parte de las revoluciones del mundo Atlántico que a ambos lados del océano pusieron en circulación discusiones sobre la libertad, igualdad, ciudadanía, representación política, soberanía, razas. También ha propuesto entender la participación de estos sectores en la fase inicial de la Independencia como un profundo proceso revolucionario. El ejemplo de la revolución haitiana y las simpatías que despertó entre sectores de la población de la provincia de Cartagena se comprendería en ese contexto internacional y de la cuenca del mar Caribe. En este sentido retrotrae el tema del interés en la igualdad a decenios antes de la crisis del imperio español por la invasión francesa (1808) y de la promulgación de la constitución de Cádiz (1812), tomados por muchos como el punto de partida de la influencia liberal en las colonias americanas. ${ }^{13}$

Por otra parte, y quizá esta sea su idea más llamativa, y al mismo tiempo discutible, propone sustraer los estudios sobre la cultura política de comienzos del siglo XIX del terreno de la paradoja entre un discurso liberal moderno y una sociedad proveniente de un pasado inmediato que hacía imposible desarrollar aquellas ideas en instituciones y prácticas políticas modernas. Propone que la salida de esa paradoja está en concebir las ideas políticas de comienzos de esa centuria como un terreno que admite diversas miradas, asimilaciones, expectativas

rios sociales y políticos", Marco Palacios (coord.), Las independencias hispanoamericanas. Interpretaciones 200 años después, Bogotá, Norma, 2009, p. 93-125.

${ }^{12}$ Marixa Lasso, Race and republicanism in the age of revolution, Cartagena, 1795-1831, University of Florida, tesis doctoral, 2002, p. 56-118; "Haiti as imagen of popular republicanism in Caribbean Colombia: Cartagena province (1811-1828)”, David Geggus (ed.), The impact of the Hatian Revolution in the Atlantic world, Columbia, University of South Carolina Press, 2001, p.176-190; Myths of harmony. Race and republicanism during the Age of Revolution, Colombia 1795-1831, Pittsburgh, University of Pittsburgh Press, 2007, p. 34-90.

${ }^{13}$ Un ejemplo de esta última interpretación con puntos de vista diametralmente opuestos a los de Lasso puede verse en Claudia Guarisco, "La Constitución de Cádiz y la participación política popular en la Nueva España, 1808-1821. Balance y nuevas perspectivas", Revista Complutense de Historia de América vol. 33, Madrid, Universidad Complutense, 2007, p. 55-70; Rafael Rojas, "Historiografía de la independencia (siglo XX)", Antonio Annino y Rafael Rojas, La independencia, México, FCE, 2008, p. 132-137. 
e interpretaciones, por parte de distintos sectores sociales y raciales. Para esta autora, la tradición colonial no desempeña ninguna función en la cultura política de la época de la Independencia. ${ }^{14}$

No es nuestro propósito debatir aquí las contribuciones de los sectores subalternos a la construcción de la nación, como tampoco las diversas vías hacia la modernidad y sus actores sociales. Lo que si nos interesa señalar para los propósitos de este artículo es que en los últimos años se viene cuestionando la tradicional dicotomía en las vías a la modernidad entre los países del Atlántico y los del área de influencia latina, como también el concebir a la modernidad en vía contraria de la tradición. Diversos estudios vienen concluyendo que la modernidad se modela sobre los elementos que le ofrece la segunda. En consecuencia, factores centrales del discurso moderno tales como nación, soberanía popular, opinión pública, ciudadanía no operaron sobre una tabula rasa, sino que se fueron deslizando a través de lenguajes, ritos, símbolos, formas societarias y demás elementos de las culturas políticas que le antecedieron. ${ }^{15}$ Ejemplo de lo anterior son los trabajos

${ }^{14}$ Marixa Lasso, "Un mito republicano de armonía racial: raza y patriotismo en Colombia, 18201812", Revista de Estudios Sociales No. 27, Bogotá, Universidad de los Andes, 2007, p. 32-45; "El día de la independencia: una revisión necesaria”, Nuevo Mundo Mundos Nuevos, París, L'Ecole des Hautes Etudes en Sciences Sociales, 2008. http://nuevomundo.revues.org/index 32872.html. (Consulta: julio 27 de 2008). En este último trabajo es fácil ver la influencia de Irene Castells, "La ciudadanía revolucionaria”, Erytheis No. 1, Barcelona, Universitat de Barcelona, 2005. http://idt.uab.es/ erytheis/castells_es.htm (Consulta: julio 17 de 2007). Uno de los argumentos centrales de quienes defienden la idea de la construcción de un proyecto moderno alternativo por parte de los sectores subordinados de algunas ciudades coloniales (Caracas y Cartagena), es que entre estos predominaban los negros y mulatos que asociaban la libertad a la República, como también al carácter portuario que las predisponía a la existencia de un cosmopolitismo desconocido en el mundo andino. Argumentos similares para el caso del Caribe insular francófono y Venezuela pero insistiendo en el fraccionamiento de la comunidad de negros y mulatos libres pueden leerse en Alejandro Gómez, “Ciudadanos de color? El problema de la ciudadanía de los esclavos y gente de color durante las revoluciones franco-antillanas, 1788-1804", Anuario de Estudios Bolivarianos No. 12, Caracas, Universidad Simón Bolívar, 2005, p. 117-157; "La Revolución de Caracas desde abajo", Nuevo Mundo Mundos Nuevos, 2008, L'Ecole des Hautes Etudes en Sciences Sociales. http://nuevomundo.revues. org/index32982.html (Consulta: julio 27 de 2008). Un balance historiográfico sobre la independencia en Colombia en Armando Martínez, "La independencia del Nuevo Reino de Granada. Estado de la representación histórica”, Manuel Chust y José Serrano (eds.), Debates sobre las independencias iberoamericanas, Madrid-Frankfurt, Iberoamericana-AHILA-Vervuert, 2007, p. 201-220.

${ }^{15}$ Jorge Conde, Buscando la nación. Ciudadanía, clase y tensión racial en el Caribe colombiano, 18211855, Medellín, La Carreta-Universidad del Atlántico, 2009, p. 101-180; M. Calderón y C. Thibaud, La majestad de los pueblos en la Nueva Granada y Venezuela 1780-1832, p. 23-40, y M. Garrido, "La Nueva Granada entre el orden colonial y el republicano: lenguajes e imaginarios sociales y políticos”, p. 93-125. 


\section{Liberalismo, ciudadanía y vecindad en Nueva Granada \\ (Colombia) durante la primera mitad del siglo XIX}

en los que se discute la relación entre la ciudadanía y la vecindad. ${ }^{16} \mathrm{El}$ argumento central de estas investigaciones es que para entender la cultura política de buena parte del siglo XIX es fundamental estudiar la dupla ciudadano/vecino, porque, al decir de Tamar Herzog, en Hispanoamérica la condición de Ciudadano/vecino implicó una construcción devenida de la tradición. Por ello, es importante comprender los cambios que sufren en el tránsito de la Colonia a la República los conceptos de vecino y ciudadano. ${ }^{17}$

Con el ánimo de contribuir a esta discusión, en este estudio nos proponemos develar ¿ cómo se concibió la ciudadanía en las Constituciones de Nueva Granada durante la primera mitad del siglo XIX? y ¿cuáles fueron las características que asumió durante este periodo? Para dar respuesta a estos interrogantes, el trabajo estudia la relación existente entre los conceptos de vecino y ciudadano, debido a que este binomio marcó las pautas con las cuales fueron concebidas las características de los ciudadanos neogranadinos en la primera mitad del siglo XIX.

La idea central que organiza nuestra reflexión es que durante la primera mitad del siglo XIX en Nueva Granada la participación de los ciudadanos en los asuntos públicos se hacía dentro de un orden corporativo y jerárquico como consecuencia de que la comunidad seguía anclada en un orden y en un imaginario tradicional. Si bien la ciudadanía política supone una ruptura completa con las visiones tradicionales del cuerpo político, ahora compuesto por individuos libres e iguales, en su versión decimonónica la ciudadanía llevaba implícita una dimensión comunitaria y una adscripción espacial en la localidad, convirtiendo a la comunidad en un importante mecanismo de regulación de los comportamientos sociales. Comportamientos que implicaban normas y valores,

\footnotetext{
${ }^{16}$ François- Xavier Guerra. "El Soberano y su Reino. Reflexiones sobre la génesis del ciudadano en América Latina”, H. Sábato, Ciudadanía política y formación de las naciones, p. 33-61; Marcelo Carmagnani y Alicia Hernández, "La ciudadanía orgánica mexicana, 1850-1910", p. 371-404; Marta Irurozqui, "De cómo el vecino hizo al ciudadano en Charcas y de cómo el ciudadano conservó al vecino en Bolivia, 1809-1830", Jaime Rodríguez (coord.), Revolución, independencia y las nuevas naciones de América, Madrid, Mapfre, 2005, p. 451-484; Tamar Herzog, Vecinos y extranjeros. Hacerse español en la Edad Moderna, Madrid, Alianza Editorial, 2006; Cristóbal Aljovín, "Monarquía o República: Ciudadano y vecino en Iberoamérica, 1750-1850", Jahrbuch für Geschichte Lateinamerikas No. 45, 2008, p. 31-55; Francisco Núñez, "El concepto de vecino/ciudadano en Perú, 1750-1850", Araucaria No. 17, Sevilla, Universidad de Sevilla, 2007, p. 235-253.

${ }^{17}$ T. Herzog, Vecinos y extranjeros. Hacerse español en la Edad Moderna.
} 
practicados y aceptados por la mayoría y eran considerados como adecuados y legítimos; por tanto, una amenaza en contra de éstos determinaba la protesta y defensa de la comunidad. Ahora bien, para entender mejor la naturaleza del cambio conceptual que la revolución de Independencia trae aparejada en lo que hace a la condición política de ciudadano, es necesario verla en relación con la del vecino, concepto que tiene raíces castellano-medievales y su esfera es la del cabildo.

\section{Entre fueros, privilegios y cargas: la categoría de vecino en la Colonia ${ }^{18}$}

En septiembre de 1850, algunos ciudadanos de Cartagena denunciaron ante las autoridades competentes que Ramón Benedetti, siendo vecino del distrito parroquial de La Catedral, aspiró y obtuvo el cargo de cabildante por el distrito del Pie de la Popa. En apartes de la denuncia manifestaban que:

Es sabido que para ser miembro de un cabildo parroquial, se necesita ser vecino del mismo distrito, más a despecho de esta disposición terminante de la ley, vemos al Sr. Dr. Ramón Benedetti, ocupando un asiento en el cabildo parroquial del Pie de la Popa, siendo vecino del distrito de la Catedral, donde como tal vecino sufragó en las elecciones de diciembre último... Denunciamos este hecho, para que se dicten por quien corresponda las providencias del caso, a fin de que se corrija el abuso. ${ }^{19}$

El argumento de los demandantes, que tenía como fin que se decretara la ilegalidad del nombramiento de Benedetti como cabildante, se amparaba en que desde 1812 hasta 1843 todas las leyes electorales de Nueva Granada establecían unos requisitos para ser acreditado como elector primario o de parroquia, así

\footnotetext{
${ }^{18}$ Las características que se establecen sobre los vecinos durante el periodo colonial fueron tomadas de Margarita Garrido, Reclamos y representaciones: Variaciones sobre la política en el Nuevo Reino de Granada, 1770- 1815, Bogotá, Banco de la República, 1993; F.-X. Guerra, "El Soberano y su Reino. Reflexiones sobre la génesis del ciudadano en América Latina", p. 33-61; Marta Irurozqui, "De cómo el vecino hizo al ciudadano en Charcas y de cómo el ciudadano conservó al vecino en Bolivia, 1809-1830", Jaime Rodríguez (coord.), Revolución, independencia y las nuevas naciones de América; T. Herzog, Vecinos y extranjeros. Hacerse español en la Edad Moderna; C. Aljovín, "Monarquía o República: Ciudadano y vecino en Iberoamérica, 1750-1850”, p. 31-55; F. Núñez, "El concepto de vecino/ciudadano en Perú, 1750-1850", p. 235-253; María Duque, "Nuevos ciudadanos: entre el imperio español y la República colombiana”, Boletín Americanista No. 60, Barcelona, Universidad de Barcelona, 2010, p. 165-186.

${ }^{19}$ Biblioteca Luís Ángel Arango (BLAA), Colección de prensa microfilmada, El Porvenir, Cartagena, septiembre 22 de 1854 .
} 
como elector secundario y poder aspirar a cargos públicos de carácter elegible. El requisito primordial era ser vecino de la localidad. Por ejemplo, la Constitución política de Cartagena de 1812 anotaba que para ejercer cualquier cargo público era necesario, además de los derechos de ciudadanía, ser hombre libre, vecino o padre de familia o tener casa poblada y vivir de sus rentas o trabajo, sin independencia de otro. De igual forma, las constituciones políticas de 1821 y 1832 señalaban que para ser elector de cualquier género y poder aspirar a cualquier cargo público era necesario la condición de vecindad, y la de 1843 señalaba: "Son sufragantes parroquiales de cada distrito los vecinos del mismo distrito y que se hallan en ejercicio de los derechos de ciudadanía". De igual forma, para ser elector de cantón se requerían las siguientes condiciones: "ser granadino en ejercicio de los derechos de ciudadanía; haber cumplido veinte y cinco años de edad; saber leer y escribir y ser vecino en el cantón en que se le nombra". ${ }^{20}$ Lo anterior nos lleva a preguntarnos ¿qué significaba la condición de vecino en el siglo XIX?, ¿qué relación guardaba con la ciudadanía? y ¿por qué se estableció como condición para acceder a cargos públicos?

En el período colonial los vecinos constituían un rango particular de moradores. Durante los siglos XVI y XVII fueron, en primer lugar, los fundadores, generalmente conquistadores; luego sus descendientes y quienes, además de la pureza de sangre, llenaban el requisito de ser propietarios y terratenientes en la población y sus alrededores. Durante estos dos siglos existían diferentes clasificaciones de vecino y su estatus dependía del nivel de riqueza que poseyera; así como en el siglo XVI el elemento principal de riqueza lo constituía la encomienda, los vecinos principales eran los vecinos encomenderos, seguido del vecino morador, que pese a ser propietario no poseía ninguna encomienda y por último se hallaba el vecino estante, cuya permanencia en el lugar era temporal. Estas clasificaciones eran utilizadas para señalar la diferencia y la valía social de cada uno de ellos. Los vecinos participaban en la elección anual de los dirigentes locales y tenían derecho legal para protestar por el comportamiento de éstos. También participaban en las solicitudes de reconocimiento de mayor estatus para

\footnotetext{
${ }^{20}$ Sobre la constitución de Cartagena de Indias de 1812 ver: BLAA, Gaceta de Cartagena de Indias, Cartagena, febrero 11 de 1813. Sobre las constituciones de 1821, 1832 y 1843 en la Nueva Granada ver: Pombo y Guerra, Constituciones de Colombia. Además ver: F. González, "Legislación y comportamientos electorales", p. 95-164.
} 
sus localidades en el interior del orden jerárquico colonial y en las protestas por abuso de jurisdicción. ${ }^{21}$

Todo esto significaba que la vecindad otorgaba un estatuto particular dentro del Reino, al ser miembro de pleno derecho de una comunidad dotada de privilegios, fueros o franquicias, puesto que todos los habitantes del Reino no eran vecinos de una ciudad. No lo eran los extranjeros, ni tampoco entre los vasallos del Rey los que dependían de un señor laico o eclesiástico, o en el caso de América, de un hacendado o los que vivían dispersos en el campo o en localidades sin estatuto político reconocido. Tampoco lo eran dentro de la ciudad los forasteros o en los pueblos, los agregados y forasteros. ${ }^{22}$ Además, ser vecino no solo consistía en poseer un rango particular, sino también en gozar de un estatuto privilegiado, lo que implicaba, por tanto, la desigualdad. Esta desigualdad, obvia en relación con los que no eran vecinos, se daba también entre los que lo eran. Por una parte, porque no existía un "vecinazgo" común a todo el Reino, si no que este estatuto dependía de los derechos específicos de la comunidad a la que se pertenecía. Además de que existía una jerarquía de privilegios entre ciudades, villas, parroquias y pueblos, algunas de estas comunidades específicas, poseían fueros particulares e incluso, dentro de una misma ciudad, villa, o pueblo, algunos vecinos poseían privilegios suplementarios que resultaban de la nobleza o la hidalguía. En este sentido, la vecindad era inseparable de una estructura y una concepción jerárquica de la sociedad..$^{23}$

Por último, la vecindad iba pareja con una concepción corporativa o comunitaria de lo social. La ciudad era uno de los cuerpos de las comunidades que constituían la sociedad. El hombre se definía por su pertenencia a un grupo, ya fuera éste de carácter estamental, racial, territorial o corporativo. No pertenecer

\footnotetext{
${ }^{21}$ M. Garrido, Reclamos y representaciones, p. 115.

${ }^{22}$ M. Garrido, Reclamos y representaciones, p. 118; F. Núñez. "El concepto de vecino/ciudadano en el Perú", p. 242.

${ }^{23}$ Esta desigualdad, diferenciación y estratificación entre vecinos era perceptible a través de los títulos de honra y reverencia, así como de las formas de tratamientos oficiales, por ejemplo el uso del Don y Doña utilizado exclusivamente durante los siglos XVI y XVII por una minoría que lo demandaba como distintivo de blancura y de nobleza. Sobre este tema ver: Jaime Jaramillo, "Mestizaje y diferenciación social en el nuevo Reino de Granada en la segunda mitad del siglo XVIII", Travesías por la historia, Bogotá, Presidencia de la República, 1997, p. 173-214.
} 
a uno de estos grupos era en la práctica estar fuera de la sociedad: vagabundos, mendigos, marginales de todo tipo. ${ }^{24}$

Ahora bien, para que los vecinos pudieran acceder a cargos elegibles como alcaldes pedáneos, cabildantes, etc., debían reunir condiciones como la pureza de sangre (no tener mezcla de las consideradas castas, ni moros, ni judíos), idoneidad (saber leer y escribir, pero en algunas aldeas esto solamente quería decir que el candidato debía ser capaz de firmar), honradez (no tener deudas con el gobierno, ni haber malversado fondos públicos), no estar acusado de crimen infamatorio, ni de ninguna falta contra la ley o la moral, ganarse la vida con un trabajo no manual. Los vecinos elegibles pertenecían a las capas más altas de una sociedad local estratificada, lo que conllevaba a una relación de particular distanciamiento entre las diversas capas sociales, manifestada en el tipo de trabajo de cada uno de ellos, fuese éste manual o no, puesto que el tener que realizar un trabajo manual implicaba cierta contaminación. Por último, existían ciertos requisitos morales: por ejemplo, el candidato no solo debía ser un buen vecino, sino buen padre, buen esposo, buen hijo, buen feligrés de su parroquia, un hombre de talento, virtuoso y patriota. ${ }^{25}$ En síntesis, el vecinazgo tenía varias dimensiones (económicas, morales y políticas) pero lo fundamental era la aceptación social de la comunidad local.

No obstante, a lo largo del siglo XVIIII se amplió el concepto de vecindad como consecuencia de las transformaciones que se estaban operando al interior de la sociedad colonial. La llegada de la dinastía de los borbones al trono español y el triunfo del absolutismo, provocó que el crecimiento del Estado fuera desplazando cada vez más las funciones y la competencia de los cuerpos en que estaba organizada la sociedad. La relación Estado-sociedad dejó de ser pensada como un vínculo de cuerpos necesariamente heterogéneos; ahora se le veía como una relación binaria y más abstracta: soberano-súbditos. La lucha contra todo poder concurrente llevó al Estado a una ofensiva contra los privilegios de los cuerpos y con ellos a una empresa de homogeneización de la sociedad. Además, durante éste siglo y por debajo de la explícita teoría política del absolutismo, se fue imponiendo un imaginario nuevo sobre la constitución de la sociedad y la naturaleza de la autoridad. Durante los dos siglos anteriores toda la teoría de la sociedad descansaba sobre un imaginario que la consideraba constituida por

\footnotetext{
${ }^{24}$ F-X. Guerra, "El Soberano y su Reino", p. 42.

${ }^{25}$ M. Garrido, Reclamos y representaciones, p. 133.
} 
grupos, lo que correspondía a la estructura social -una sociedad estamental- e incluso política -la estructura plural de la monarquía- existente hasta la época. Ahora se trataba de un conjunto de mutaciones en el campo de las ideas, del imaginario, de los valores, de los comportamientos. ${ }^{26}$ Se operó un cambio fundamental sobre la concepción del hombre, que nace en un orden social dado de antemano e inmodificable por ser un régimen de castas a una concepción del hombre más antropológica e histórica, de un hombre que se construye gracias a sus esfuerzos y a un proyecto de vida.

En estas transformaciones el mestizaje desempeñó un papel central al imponerle condiciones al reacomodo del orden social, en especial a lo que tenía que ver con la valoración social positiva de las personas y familias gracias a la construcción de una vida meritoria, tanto personal como familiar, a punta de esfuerzos, sacrificios y la proyección social de una conducta aceptada y valorada por los demás. En consecuencia, al lado de la tradicional prestancia social determinada por la raza, los abolengos y los orígenes familiares paulatinamente fue surgiendo otra, la determinada por el autoesfuerzo, por los méritos y el reconocimiento social logrados gracias a la práctica de unas virtudes que el conjunto social consideraba como dignas y honorables. Esto fue favorecido por los nuevos elementos ideológicos y científicos que para finales de la Colonia habían introducido a nivel intelectual y administrativo una visión más antropológica e histórica del hombre, concebido ahora como un ser en construcción, y por tanto posible de perfección, abriendo una brecha en una sociedad de castas que solo reconocía los méritos personales y la valía social en el caso de quienes los heredaban de cuna, es decir, a los blancos considerados limpios de sangre y que vivían sometido a Dios y al Rey. A su vez, todo esto produjo procesos de diferenciación social entre los estratos más bajos de la población, como también luchas por la superación de algunas barreras de diferenciación social como era el factor racial. ${ }^{27}$

Así, en 1766 la corona "impuso" a las municipalidades más importantes controladas por oligarquías hereditarias, la elección por todos los vecinos de los

\footnotetext{
${ }^{26}$ F-X. Guerra, Modernidad e independencias.

${ }^{27}$ Sergio Paolo Solano, "Modelos bipolares, estilos de vida y capas medias en la historiografía social colombiana sobre el siglo XIX”, Clío América vol. 3, No. 6, Santa Marta, Universidad del Magdalena, 2009, p. 193-213; "Los sectores sociales medios en la Colombia del siglo XIX", Memorias No. 13, Barranquilla, Universidad del Norte, 2010.
} 
diputados y del síndico personero del común. ${ }^{28}$ A partir de este momento todos los vecinos, en el plano formal, eran elegibles ya que no necesitaban distinción de estado de ninguna naturaleza; solo se exigía ser un hombre de honor, ya no fundamentado en un privilegio de sangre y de cuna y patrimonio exclusivo de los blancos, sino como un honor basado en un código de buen vecino y parroquiano, honrado, trabajador, de buen trato con todos, respetuoso y acatador de las autoridades, buen padre, buen esposo, buen hijo y buen hermano, cumplidor con deudas y diezmos, etc., por lo que podían recaer en nobles y plebeyos por ser enteramente dependiente del concepto público. ${ }^{29}$ Aunque esta ley no llegó a feliz término, la decisión de la elección de las autoridades municipales por todos los vecinos correspondía a una creciente demanda de los nuevos "notables" de las ciudades y villas.

Como complemento de los cambios que seestaban operando a nivel estructural, la dinastía de los borbones implementó diversas reformas a nivel económico, político, social y cultural que empujaron a la población mestiza, india y mulata a procurarse un nuevo estatus jurídico y social que les reconociera la condición de vecino como prerrequisito para acceder a mayores privilegios en el interior del orden estamental. Marcelo Carmagnani y Alicia Hernández encontraron que en México el segmento de los notables acrecentó en sus respectivas sociedades sus derechos y privilegios en virtud de la reorganización borbónica. Sin embargo, no fueron los únicos que se beneficiaron, pues otros grupos de la sociedad como mulatos, indios y mestizos, también aprovecharon los intersticios que dejaron estas reformas para introducirse en el orden de los notables, como consecuencia de que la nueva organización política y administrativa buscó ante todo calar en el conjunto del pueblo. ${ }^{30}$

\section{Entre derechos y deberes: ciudadanos y vecinos durante la primera mitad del siglo $X I X$}

Después de lograda la Independencia e iniciado el proceso de construcción de la nación en la Nueva Granada, se reconoció la igualdad de los individuos mediante el otorgamiento de derechos civiles y de derechos políticos consignados

\footnotetext{
${ }^{28}$ Este funcionario representaba a los intereses de la comunidad, en especial en lo relacionados con el uso de los bienes del común (ejidos, aguas, bosques, pastos).

${ }^{29}$ M. Garrido, "Honor, reconocimiento, libertad", p. 99-121.

${ }^{30}$ M. Carmagnani y A. Hernández, “La ciudadanía orgánica mexicana, 1850-1910”, p. 372.
} 
en la ciudadanía. Sin embargo, se estableció una diferencia radical entre ciudadanía civil o inactiva y ciudadanía política o activa, subrayándose la universalidad de la primera y las limitaciones que debían imponerse a la segunda. Gozaban de la ciudadanía política los que podían votar, elegir y ser elegidos; todos los demás, la mayoría de la población, eran ciudadanos civiles o inactivos, solo beneficiarios de la nacionalidad como consecuencia de que para adquirir la ciudadanía política se establecieron condiciones claras y pocas discutidas como la edad, el sexo y se estipuló una renta para acceder a los derechos políticos, lo que implicó la negación de éstos derechos a los esclavos, los menores de edad, las mujeres y los que no poseyeran bienes o rentas. Estos solo fueron otorgados a los sectores privilegiados como hacendados y terratenientes y a los sectores intermedios como comerciantes, abogados, militares y artesanos, principalmente tipógrafos, sastres, maestros de obras, orfebres, etc. ${ }^{31}$

No obstante, aunque el ciudadano se convirtió en el elemento central de la "Nación" aún siguió persistiendo la condición de vecindad como necesaria para ser sufragante, elector y aspirar a cargos públicos elegibles. Las explicaciones de la permanencia de este hecho son diversas. John Lynch señala que aunque la independencia fue una gran tormenta que destruyó los lazos que ataban a Hispanoamérica con España y el armazón del gobierno, dejó intactos los cimientos de la sociedad colonial impidiendo la centralización estatal. ${ }^{32}$ Por ello, según Gonzalo Sánchez, la primacía de la vecindad reflejaba una inocultable realidad: era una expresión del arraigo y del vigor del provincialismo, de la pluralidad política y social, de la fragmentación política-territorial; en una palabra, de los particularismos tan extendidos en el subcontinente, producto de la herencia colonial. ${ }^{33} \mathrm{Y}$ es que la mayoría de los países latinoamericanos después de lograda la independencia atravesaron por el problema de construir un Estado-Nación centralizado, debido a que los antiguos centros de poder político que venían de la Colonia no querían someterse a una autoridad central y por tanto perder las autonomías económicas y políticas de que gozaban. La debilidad de los nuevos

\footnotetext{
${ }^{31}$ Roicer Flórez y Sergio Paolo Solano, "Educando al buen ciudadano. Las guardias Nacionales en la Provincia de Cartagena, Colombia, 1832-1853”, Anuario de Estudios Americanos vol. 62, No. 2, Sevilla, Escuela de Estudios Hispanoamericanos, 2010 (en prensa).

${ }^{32}$ John Lynch, The Spanish American revolutions, 1808-1826, New York, 1973, p. 356.

${ }^{33}$ Gonzalo Sánchez, "Ciudadanía sin democracia o con democracia virtual”, H. Sábato, Ciudadanía política, p. 433.
} 
Estados se vio reflejada en muchos aspectos, siendo uno de ellos la persistencia de la vecindad, permitiéndole a cada región, ciudad y villa tener pleno control sobre los habitantes de su territorio. ${ }^{34}$

Nueva Granada no era ajena a esta realidad. Al momento de la Independencia se caracterizaba por no existir como una verdadera unidad política-administrativa. A lo largo y ancho de su territorio existía una fragmentación provincial producto de su accidentada geografía y de la escasez de vías de comunicación adecuadas. Lo que existió desde la Colonia y bien avanzada la República fue un mosaico de sociedades regionales con sus particulares economías, prácticas culturales y elites locales. ${ }^{35}$ Debido al escaso intercambio de población y comercio entre las provincias surgieron tipos regionales de población, rivalidades entre las provincias y sobre todo una adhesión y amor a la localidad y a la provincia en vez del Virreinato. En particular, eran reconocibles las regiones de la Costa, Antioquia, Cauca, Santander, Cundinamarca y Boyacá. Regiones que se diferenciaban en sus prácticas sociales, en la forma de asumir sus relaciones con los otros hombres y con la naturaleza, en las relaciones de poder y de dominación que se instauran, en la apropiación y formas de ordenamiento territorial, en los tintes y grados de mestizaje, en las mentalidades desde las cuales abordan su quehacer social, lo que produjo la construcción de prácticas culturales que alcanzaron a incrustarse en las diferentes manifestaciones de la vida cotidiana y en la forma particular de asumir las relaciones sociales en el más amplio sentido del término. ${ }^{36}$

Estas regiones se diferenciaban con relación a las otras: son conscientes de su particularidad y se reconocen en ella como condición de su existencia independiente. Verbigracia, en 1835 Juan José Nieto le escribió una carta al general Francisco de Paula Santander en la que además de señalar las ventajas económicas y políticas que según él le reportaría a la Costa el federalismo, también enumeró las diferencias culturales como la forma de hablar y el vestir que habían entre esta región y el interior andino. En apartes de la carta, Nieto se quejaba

\footnotetext{
${ }^{34}$ M. Carmagnani y A. Hernández, "La ciudadanía orgánica mexicana”, p. 371-404. Sobre el caso de la persistencia de la vecindad en América Latina durante la primera mitad del siglo XIX, ver el trabajo de F-X. Guerra, "El Soberano y su Reino", p. 33-61.

${ }^{35}$ Marco Palacios, "La fragmentación regional de las clases dominantes en Colombia: Una perspectiva histórica”, Estado y clases sociales en Colombia, Bogotá, Procultura, 1986, p. 87-149.

${ }^{36}$ María Uribe y Jesús Álvarez, Poderes y regiones: problemas en la construcción de la nación colombiana, 1810-1850, Medellín, Universidad de Antioquia, 1987, p. 47.
} 
de las burlas expresadas por las gentes del interior hacia la educación de los cartageneros, su "modo de hablar", la tendencia a ridiculizar chocantemente sus costumbres”. Años más tarde, Rafael Núñez también se quejaría de las críticas que se hicieron a los Estados de la Costa durante el año de su candidatura presidencial "las designaciones odiosas....contraídas a la raza y los hábitos industriales" que predominan en la región. ${ }^{37}$

Cabe señalar que este fraccionamiento del territorio no solamente se presentaba de región a región, sino que también se daba en el interior de éstas. En 1852, la Sociedad Democrática de Barranquilla le recordó al Congreso que era su deber dar satisfacción a lo que la opinión pública demandaba y le exigía adquirir autonomía política y económica con respecto a Cartagena. Entre las razones que esbozó la Sociedad se encontraban el área extensa de los cantones de Barlovento, su posición geográfica, su comunidad de intereses pero sobre todo las diferencias que existían en el vestuario y las costumbres entre los habitantes de Barlovento y Cartagena. ${ }^{38}$

La existencia de estas regiones en Nueva Granada durante la primera mitad del siglo XIX, también es perceptible a través del lenguaje político de la época. En la percepción de un cartagenero de la primera mitad del siglo XIX, el país coincidía con la jurisdicción de la provincia de Cartagena, por oposición a las jurisdicciones de, por ejemplo, Santa Marta o Santa Fe. Esta reducción imaginaria del país a las dimensiones de la provincia en que se ha nacido, o mejor dicho esta identificación de la provincia con el país, es el punto de partida del imaginario político de los nuevos ciudadanos de las provincias neogranadinas de la primera mitad del siglo XIX. En la imaginación de los neogranadinos la patria era la tierra nativa, el país comprendido por la tradicional jurisdicción provincial. ${ }^{39}$ Así lo hacen saber algunos vecinos de Cartagena en 1843, luego de haber elevado una

${ }^{37}$ Juan José Nieto, "Una temprana argumentación a favor del federalismo, carta dirigida al General Santander", Gustavo Bell (Comp.), Selección de textos políticos, geográficos e históricos, Barranquilla, Departamento del Atlántico, 1993; Eduardo Posada, "El regionalismo político en la Costa Caribe de Colombia", Aguaita No. 1, Cartagena, Observatorio del Caribe Colombiano, 1999, p. 9-23.

${ }^{38}$ Robert L. Gilmore, El federalismo en Colombia, 1810-1858, tomo1, Bogotá, 1995, p. 48. Sobre el fraccionamiento territorial al interior de la Provincia de Cartagena durante el periodo colonial ver: Jorge Conde, Espacio, sociedad y conflictos en la provincia de Cartagena, 1740-1815, Barranquilla, Universidad del Atlántico, 1999, p. 1-86.

${ }^{39}$ Armando Martínez, El legado de la Patria Boba, Bucaramanga, Universidad Industrial de Santander, 1998, p. 25-26. Además ver François-Xavier Guerra, "La identidad republicana en la época 
representación ante las autoridades provinciales solicitando que el soldado Luís Cayetano Barrios, vecino de la provincia de Mariquita, fuese dado de baja porque él no era un vago como se decía en los informes de las autoridades provinciales sino un ciudadano honrado. Para los vecinos era escandaloso que un padre de familia, pacífico y laborioso ciudadano, leal a sus deberes y que había figurado en los trastornos pasados con honor y patriotismo "se vea por mandato de sus enemigos enrolado en el ejército por vago, privado de sus bienes, que sufrirán notables pérdidas, y condenado a la indigencia en país ajeno", ${ }^{40}$ es decir en la provincia de Cartagena.

Fue el fraccionamiento territorial lo que llevó a que las autoridades republicanas establecieran que cada localidad, región o territorio reafirmara a sus miembros la condición de vecinos, dejando claro la incapacidad del Estado para someter e imponer su autoridad a las regiones y localidades, las que gozaban de autonomías políticas y económicas sobre sus habitantes. Lo anterior demuestra que las constituciones políticas, a pesar de ser el triunfo de la ideología liberal, consignaron fuertes referencias del Antiguo Régimen que en la práctica permitieron garantizar la fidelidad de los territorios en que se aplicaban. Por más que la República supuso un cambio de régimen, este no pudo romper los lazos en que se había ido concibiendo el ejercicio de la ciudadanía a partir del vecino. La vecindad implicó una construcción local y devenida de la tradición. ${ }^{41}$

Ahora bien, con el advenimiento de la República la vecindad sufrió algunos cambios. El principal fue que mientras en la Colonia solo un grupo reducido de la población gozaba de este privilegio, con la República estos fueron otorgados a la mayoría de los habitantes. Solo estaban excluidos los forasteros y residentes, los que se diferenciaban de los vecinos porque los primeros no podían intervenir en los asuntos públicos como electores o elegibles y los segundos, al igual que no participaban en dichos asuntos, solo eran considerados residentes si permanecían en la localidad, pero la perdían al salir del lugar.

de la independencia”, Emma Wallis y Gonzalo Sánchez (eds.), Museo, Memoria y Nación, Bogotá, Museo Nacional de Colombia, 2000, p. 253-284.

${ }^{40}$ BLAA, Semanario de la Provincia de Cartagena, Cartagena, septiembre 10 de 1843.

${ }^{41}$ F. Núñez, “El concepto de vecino/ciudadano en Perú (1750-1850)”, p. 235-253; T. Herzog, Vecinos y extranjeros. Hacerse español en la Edad Moderna. 
Pero ¿cómo se definía y se obtenía la vecindad durante la primera mitad del siglo XIX en Nueva Granada? La Constitución política de 1832 definía como vecino para el efecto de sufragar "el que haya residido en un distrito parroquial por un año por lo menos antes de la elección, o manifestado ante la autoridad legal competente, conforme a la ley, el ánimo de avecindarse en él”42 y en 1843 el gobernador de la provincia de Cartagena publicó en el periódico oficial un decreto titulado "Diferencia de derechos por razón de la vecindad" en el que anotaba:

Art. 51. Son vecinos de un distrito parroquial los individuos que se hallan radicados en él, con casa habitada por ellos o por sus familias, la mayor parte del año. Son vecinos de cualquier otra sección territorial más extensa que el distrito, todos los que lo sean en uno de los distritos que componen dicha sección.

Art. 52. Adquiere vecindad en un distrito el que declara ante el funcionario que en él está encargado de promulgar las leyes, que quiere ser vecino, siempre que al hacerlo tenga su residencia habitual dentro del distrito. Esta declaración solo pueden hacerla las personas que no están bajo la dependencia doméstica de otro.

Art. 53. También se adquiere la vecindad por uno de los hechos siguientes: 1. Vivir constantemente en el distrito por más de un año; 2. posesionarse de un destino público que obligue a residir en aquel distrito y cuya duración sea indefinida o más de un año. ${ }^{43}$

Así, para ser vecino no era necesario el requisito de la propiedad, si se exceptúa el requisito del solar (afincado). Además, una persona que no era natural de un determinado distrito y deseaba obtenerla la podía adquirir declarando ante un funcionario público su deseo de avecindarse en dicho distrito siempre y cuando no dependiera de otro. Los funcionarios públicos adquirían la vecindad en el lugar en donde laboraban. Ahora bien, es preciso señalar que la condición de la vecindad funcionaba en diferentes grados. Por ejemplo existía una vecindad a nivel distrital en la que los vecinos poseían sus derechos y deberes. No obstante, también existía la vecindad a nivel cantonal y nivel provincial. Es decir, los habitantes del distrito parroquial de Santo Toribio eran vecinos de ese distrito pero también lo eran del cantón de Cartagena y de la provincia del mismo nombre

\footnotetext{
${ }^{42}$ Pombo y Guerra, Constituciones politicas de Colombia.

${ }^{43}$ BLAA, Semanario de la Provincia de Cartagena, Cartagena, mayo 3 de 1843.
} 
y sus derechos y obligaciones comenzaban y terminaban en los límites de éstas entidades territoriales.

De igual forma, la condición de vecindad se perdía por el hecho de adquirirla en otro distrito y por permanecer ausente del distrito por más de tres años, estando dentro del territorio de la República. En el caso de las mujeres casadas que vivieran unidas a sus maridos, adquirían y perdían la vecindad por los hechos que se las hacían adquirir y perder a éstos Por su parte, los menores que se encontraban bajo la patria potestad, o los que se hallaban bajo la guarda de un tutor, no tenían otra vecindad que la del padre o tutor respectivo y los extranjeros podían adquirir el derecho de vecindad lo mismo que los nacionales.

En cuanto a los derechos que representaba se encontraban que solo los vecinos podían ser albaceas dativos y testigos en los actos solemnes o auténticos, salvo las excepciones que se establecían por urgencia o necesidad. El código judicial establecía los casos en que la vecindad daba derecho para sustraerse a la jurisdicción de los jueces y tribunales que eran los del vecindario. Finalmente, la constitución y las leyes respectivas fijaban los demás derechos civiles y políticos que se concedían a los vecinos; pero en todo caso, el hecho de serlo se decidía por lo determinado en éste título. ${ }^{44}$ Además, de cumplir con sus deberes en su distrito parroquial, los vecinos que gozaran de los derechos de ciudadanía debían ejercer sus derechos como votantes, electores, aspirantes a cargos públicos e integrar la Guardia Nacional por el mismo distrito parroquial y provincia a que estaban adscritos. No estaba permitido por la ley que un individuo poseyendo los derechos de ciudadanía sufragara o aspirase a cargos públicos por un distrito parroquial diferente al suyo como se pudo apreciar en el caso citado más arriba.

En definitiva, aunque con la Independencia se abolió el régimen de castas, las personas (en este caso los vecinos) al igual que en el periodo colonial, seguían adscritos a una comunidad de tipo social antiguo: la localidad, en la cual poseían todos sus derechos y obligaciones, reafirmando los lazos corporativos o comunales. Esto posibilitaba que el individuo, figura abstracta que solo tenía un uso discursivo, se disolviera en la comunidad local que tenía un dominio completo sobre él y que constituía la unidad fundamental de la sociedad. La parroquia era, en efecto, la célula básica de la sociedad tradicional: una comunidad muy fuerte

\footnotetext{
${ }^{44}$ BLAA, Semanario de la Provincia de Cartagena, Cartagena, mayo 3 de 1843.
} 
unida por estrecho vínculos de parentesco y solidaridad material. La seguridad, los negocios, la política, etc., eran asuntos colectivos. ${ }^{45}$

Sin embargo, la persistencia de la vecindad se convirtió en un problema para que el Estado ejerciera su autoridad. Por ejemplo, las mismas autoridades provinciales se excusaban de perseguir, capturar y mandar los reemplazos de los desertores del ejército, argumentando que los soldados prófugos no eran vecinos de su parroquia, como ocurrió en la provincia de Cartagena en 1843: "Ha notado la gobernación que algún jefe político, al pedírsele los reemplazos no los remite, fundándose en que los desertores no son vecinos de su cantón, aunque como tales aparecen en sus respectivas filiaciones". O algunas veces los vecinos se excusaban y se negaban a cumplir con sus deberes, como el pagar el servicio personal subsidiario, argumentando ser vecinos de otros distritos como ocurrió en la parroquia de Santa Rosa en 1849. El gobernador de la provincia de Cartagena señalaba que: "visto el presente oficio de la jefatura política de este cantón en que manifiesta que algunos individuos residentes en el distrito de Santa Rosa se excusan de prestar allí el servicio personal subsidiario diciendo ser vecinos de otros distritos..." 46

Nada ilustra mejor la fuerza y la influencia de la vecindad en la nueva Granada durante la primera mitad del siglo XIX como la institución militar de la guardia nacional. Si bien ésta estaba conformada por ciudadanos, éstos tenían que defender solamente los límites de su provincia. No era permitido por la ley movilizar a los vecinos que hacían parte de la guardia nacional a otra provincia. Por ejemplo, en el año de 1839, durante la Guerra de los Supremos, el general Joaquín Posada Gutiérrez solicitó la movilización de cincuenta hombres armados de la guardia nacional de la provincia de Cartagena para ser conducidos a someter un levantamiento armado en la de Santa Marta. Entre las razones que se señalaron para no aprobar ésta medida se encontraba: "el artículo 69 de la ley orgánica de provincia, señala que de ninguna manera se sacará del cantón para provincia diferente a la guardia nacional... hacer lo contrario es quebrantar la ley". ${ }^{47}$

\footnotetext{
${ }^{45}$ F-X. Guerra, "El Soberano y su Reino", p. 33-61.

${ }^{46}$ BLAA, Semanario de la Provincia de Cartagena, Cartagena, septiembre 22 de 1844 y agosto 20 de 1845.

${ }^{47}$ Archivo Histórico de Cartagena, Fondo milicias y Militares, Cartagena, enero 5 de 1839.
} 
En ciudades como Cartagena, conformada por los distritos parroquiales de La Trinidad, Santo Toribio y La Catedral, la vecindad se convertía en un problema serio debido a que los habitantes cambiaban de residencia dentro de la misma ciudad. La estrategia utilizada por muchos empleados públicos (de carácter no remunerable) que no querían seguir ejerciendo los cargos era cambiar su residencia a otro distrito parroquial, como ocurrió en Cartagena en el año de 1840. El caso que mostramos a continuación es muy ilustrativo para lo que estamos intentando demostrar y en el cual se vieron envueltos el juez parroquial del distrito de Santo Toribio, el Concejo Municipal y el Jefe Político del cantón de Cartagena.

En el mes de marzo se le concedió una licencia por treinta días al juez del distrito parroquial de Santo Toribio, Agustín Palas, con el compromiso de asumir el cargo una vez terminada dicha licencia. Cumplida ésta, el alcalde del distrito de Santo Toribio le instó a que volviese al ejercicio de sus funciones. No obstante, en contestación a esta solicitud, Palas le mostró una representación que dirigió al concejo municipal de Cartagena en donde renunciaba al destino por haber mudado de domicilio a la parroquia de la Catedral, cuya circunstancia la apoyaba en una boleta dada por el alcalde de ese distrito en la cual constaba "que el señor Palas le manifestó que se había avecindado en dicha parroquia". Sin embargo, el alcalde de Santo Toribio le escribió "que aunque había dado curso a su representación, debía encargarse del juzgado y continuar desempeñándolo hasta tanto fuese exonerado por el concejo municipal". En respuesta a esta nota, Agustín Palas contestó negándose a encargarse del juzgado amparado en la siguiente razón: "fundado en que por el artículo 182 de la Constitución ningún granadino puede ser distraído de sus jueces naturales, y que no siendo él vecino de la parroquia de Santo Toribio, no podía serlo de aquella parroquia”.

Además agregaba: por otra parte, viviendo yo en la parroquia de La Catedral ¿podré ser juez de los vecinos de Santo Toribio?, ¿con razón no se imprimiría una nulidad permanente en todas aquellas cosas en que yo ponga mi mano?, ¿mil responsabilidades no me acarreará la determinación del jefe político a mi cualidad de ciudadano neogranadino? Finalmente, Agustín Palas fue obligado por el Jefe Político del cantón de Cartagena a encargarse del juzgado, pero sobre todo a volver a su antigua residencia en el distrito de Santo Toribio y adquirir nuevamente la vecindad en ese distrito para que no existiera ningún impedimento 
de orden legal. Entre las razones que esbozó el jefe político se encontraban las siguientes:

Es incuestionable que conforme al artículo 200 de la Constitución, los granadinos tienen la libertad de mudar de domicilio, de ausentarse de la República y volver a ella; pero el mismo artículo añade que sea observando las formalidades legales. Estas formalidades no son otras, que las de no tener ninguna causa que le impida el ausentarse de la parroquia como en el caso lo es, la de tener a su cargo una judicatura parroquial que legalmente se le confirió y que el juró desempeñar sin protestar, ni alegato alguno.

....El destino de juez parroquial tiene por ley la duración de un año, y en el hecho de aceptarlo queda comprometido el nombrado a residir en le lugar por todo el tiempo de la duración del destino, a menos que antes se le exonere de él legalmente. Si se autoriza un procedimiento como el del señor Palas, no sería difícil que el alcalde y jueces de parroquia huyendo de las cargas concejiles se ausentasen todos a la vez, y mudasen de vecindario, y algunas poblaciones que están divididas en varios distritos parroquiales, como ésta ciudad, en donde se muda de vecindario pasándose al frente de la calle.... ${ }^{48}$

Así, hacia mediados del siglo XIX encontramos en Nueva Granada una vecindad que cobra significado en su dimensión territorial, social y política y que representaba para quienes tenían ese rango derechos y deberes, que no los poseían los forasteros y residentes, aunque su nivel de riqueza, ingreso o profesión fuera similar o superior a los reputados por vecinos.

\section{Honor, reconocimiento social y mecanismos de control social: la influencia de la comunidad}

Es necesario señalar que durante la primera mitad del siglo XIX en Nueva Granada a la categoría de vecino se le adjuntaron unas condiciones de tipo moral, estableciéndose una notoria diferencia entre buen y mal vecino. El ser catalogado como lo uno o lo otro era una condición cualitativa que se acreditaba solo a partir de la realidad local en la cual operaba la persona. Es decir, para que una persona fuese reputada como buen vecino era necesario ser reconocido como buen padre, buen esposo, buen hijo, buen feligrés, no estar acusado de ninguna falta contra la ley ni la moral, ser una persona virtuosa, etc. ${ }^{49}$ En síntesis, se necesitaba tener lo

\footnotetext{
${ }^{48}$ BLAA, La Ronda, Cartagena, abril 16 de 1840.

${ }^{49}$ M. Carmagnani y A. Hernández, "La ciudadanía orgánica mexicana”, p. 375.
} 
que en la época se denominaba un modo honesto de vivir o ser estimado por la honradez de su casa.

Esos atributos se demandaban para que los ciudadanos pudieran aspirar y desempeñar algún cargos públicos. Esto necesariamenteimplicaba el conocimiento de la vida del aspirante, ya que dada la particular combinación de cualidades requeridas en el candidato, su vida privada no se entendía como separada de la vida pública y podía ser objeto de debate, testimonio y juicio en la arena pública, debido a que los vecinos tenían derecho a protestar por el comportamiento de los empleados públicos. Era una práctica de la época que los alcaldes de los distritos parroquiales debían leer la lista de los vecinos que podían votar y aspirar a los cargos públicos; luego era colocada en un lugar visible con el objeto de que cada uno de los vecinos dijera lo que sabía de los aspirantes y electores sobre sus cualidades personales, género de vida, calidad de vida u ocupación y hablara sobre sus defectos. ${ }^{50}$ Por ejemplo, en 1853, el diario El Monitor del Pueblo publicó la ley de elecciones aprobada ese año, la que señalaba:

Copia de la lista de qué habla el artículo 1, será fijada en un lugar público, a lo más tarde el día 10 de Julio y permanecerá fijada hasta que terminen las elecciones. Todo ciudadano-vecino del distrito tiene derecho a ser incluido en la lista de electores; y el que no haya sido, lo será precisamente por reclamación suya, hecho personalmente ante el jurado, probando que tiene las cualidades morales necesarias. Además también queda a cualquier ciudadano, el derecho de hacer reclamaciones, para que se borren de la lista los que, estando incluidos en ella, carezcan de las cualidades morales y de las cualidades de ciudadanos vecinos del distrito. ${ }^{51}$

Era el conocimiento personal y el juicio valorativo que la comunidad confería a la persona el que lo convertía en buen o mal vecino, lo distinguía del residente y del forastero. Esto se debía en buena parte a lo expuesto que estaba en Nueva Granada durante la primera mitad del siglo XIX la vida privada. No era posible en realidad crear grandes distancias sociales y nichos invisibles en un país en donde el espacio natural en que se desenvolvía la vida era la localidad. Las intimidades de los hombres políticos se convertían rápidamente en asunto de dominio público y entraban a formar parte decisiva del juicio que sobre ellos

\footnotetext{
${ }^{50}$ M. Garrido, Reclamos y representaciones, p. 123.

${ }^{51}$ BLAA, El Monitor del Pueblo, Cartagena, agosto 20 de 1853.
} 
se emitiera. ${ }^{52}$ Por ejemplo, en 1840 fue designado Juan Antonio Calvo para la cámara de representantes por la provincia de Cartagena, sin embargo el diario El Tiempo anotaba que Calvo no podía ejercer dicho cargo porque no reunía las condiciones establecidas por la constitución política de Nueva Granada. En apartes del artículo publicado por el diario se señalaba lo siguiente:

Desde que el hombre se encuentra en un puesto público ya su vida entera y sus buenas o malas cualidades son del dominio de la sociedad, porque de ellas va a depender la observancia o desobediencia a la ley escrita. Se nos ha remitido un artículo sobre la nulidad del nombramiento del Sr. Juan Antonio Calvo para Representante por ésta Provincia, y aunque por su extensión y porque deseamos evitar personalidades e insultos, nos hemos negado a insertarlo, como las ideas nos han parecido exactas, las emitimos excitando a la Cámara de Representantes a que examine la verdad de los hechos. El Sr. Calvo carece de la propiedad exigida por el Artículo 54 de la Constitución, pues una casa apenas regular y la imprenta, únicos bienes conocidos a su familia, no le pertenecen exclusivamente, sino que son coherederos sus hermanos en número según creemos de seis, además de que la casa tiene gravámenes considerables. Esta propiedad no puede suplirse con la renta porque el producto de la imprenta en su séptima parte, ni el insignificante provecho de la tesorería de rentas provinciales puede alcanzar a 400 pesos anuales. ${ }^{53}$

El honor de la casa no era un bien privado sino público. El comportamiento estaba limitado por la observancia del vecindario del cual se formaba parte y de cuya mirada dependía la reputación y el honor. ${ }^{54}$ En una sociedad en donde todo se veía y todo se comentaba, el ocultamiento de su pérdida o el desprecio de su valor eran delatados por la comunidad. A través de actos simbólicos, de rumores, de injurias verbales y de escritos satíricos los vecinos ejercían un control y un castigo a quienes lo perdían. La mejor referencia de esto la constituía la expresión "público y notorio", lo cual se refería a lo sabido por todos e incluía los distintos aspectos de la vida de los vecinos en la calle, la plaza, la iglesia o

\footnotetext{
${ }^{52}$ Francisco Gutiérrez, Curso y discurso del movimiento plebeyo, 1849-1854, Bogotá, IEPRI, 1995, p. 45

${ }^{53}$ BLAA, El Tiempo, Cartagena, junio 20 de 1840; S. P. Solano, "Los sectores sociales medios en la Colombia del siglo XIX”; Sergio Paolo Solano y Roicer Flórez, "Historia social y literatura en Colombia a comienzos del siglo XX. Los sectores sociales medios en la novela Cosme de José Félix Fuenmayor", Revista de Indias vol. No. 251, Madrid, Consejo Superior de Investigaciones Científicas, 2011 (en prensa); “Imprentas, tipógrafos y estilos de vida en el Caribe colombiano, 1850-1930", Palobra No. 9, Cartagena, Universidad de Cartagena, 2008, p. 125-144.

${ }^{54}$ F. Núñez, "El concepto de vecino/ciudadano en Perú, 1750-1850”, p. 245.
} 


\section{Liberalismo, ciudadanía y vecindad en Nueva Granada \\ (Colombia) durante la primera mitad del siglo XIX}

el cabildo y en ocasiones la vida de las personas dentro de sus casas. En una vida de tanta proximidad y tanta vecindad, las reglas de la comunidad imponían cierta disciplina cuyo quebrante recibía una sanción de carácter ritual o también punitiva. $^{55}$

La comunidad constituía un importante mecanismo de regulación de los comportamientos sociales. Estos comportamientos implicaban valores morales y sociales practicados y aceptados por la mayoría y eran considerados en consenso como adecuados y legítimos; por tanto, una amenaza en contra de éstos determinaba la protesta y defensa de la comunidad. El poder y la influencia de esta se ejercía en todos los aspectos de la vida de los vecinos. Una de las esferas en las que se evidenciaba este poder era en las relaciones laborales. Verbigracia, los trabajadores independientes requerían de fiadores, de responsables de su comportamiento, de un ciudadano de reconocida solvencia económica y moral que avalará ante las autoridades la bondad de su quehacer, su dedicación al trabajo y la idoneidad de su persona; es decir que los recomendara. Esto es observable a través de la documentación notarial de la primera mitad del siglo XIX que contienen la expresión ritual y formal: "ciudadano y vecino de esta ciudad a quien doy fe que conozco".

De igual forma, dados los lazos de comunidad, aún durante la primera mitad del siglo XIX las penas contra los delitos consistían básicamente en el destierro y la vergüenza pública. El primero se hacía con el objeto de marginar al individuo debido a que el hombre se definía por su pertenencia a un territorio y el que no lo estaba era en la práctica un vagabundo, un mendigo, en definitiva un marginal. Por otro lado, el escándalo o la famosa "pública voz y fama" eran las formas de sanción que la comunidad empleaba contra quienes transgredían el orden social y afectaban muy especialmente -por supuesto- a quienes vivían en una alta estima social. La comunidad castigaba a sus miembros haciendo público aquello que se quería mantener en secreto. Además se sacaba al condenado de la "cárcel” y se le

\footnotetext{
${ }^{55}$ Verónica Undurraga, "El honor no es más que la buena opinión: aproximación al honor a partir de la categoría de lo público en el Chile de 1792 a 1822”, Bicentenario vol. 4, No. 2, Santiago de Chile, Centro de Estudios Bicentenario, 2005, p. 17-35; "Honores transversales, honores polisémicos en la sociedad chilena del siglo XVIII", Alejandra Araya, Azun Candina y Celia Cussen (eds.), Del Nuevo al Viejo Mundo: Mentalidades y representaciones desde América, Santiago, Universidad de Chile, 2008, p. 53-65.
} 
hacía recorrer las principales calles de la ciudad, acompañado del pregonero que gritaba el nombre del prisionero y el delito cometido.

Algunas veces era más importante para desempeñar cargos públicos el ser considerado por la comunidad como buen vecino que el poseer los derechos de ciudadanía. Verbigracia, en Cartagena en el año de 1847 fueron elegidos algunos jueces parroquiales y alcaldes sin tener los derechos de ciudadanía, pero eran considerados por la comunidad como hombres de honor y buenos padres:

Hoy debe reunirse el cabildo abierto porque para hoy ha sido convocado para admitir o no la renuncia que de juez suplente parroquial ha hecho el Sr. José María Vives; por consiguiente, caso que se admita es necesario que el cabildo piense bien a quien nombra y que no sea solo buen vecino, buen padre de familia, honrado y apto para desempeñar el destino, si no que tenga las cualidades requeridas por la constitución, es decir, ser granadino en ejercicio de los derechos de ciudadano, pues el año pasado se han elegido jueces parroquiales sin tener las cualidades de ciudadano y hasta ahora ha quedado todo en silencio, así como también la elección de un alcalde que no hace poco ha sido nombrado sin tampoco tener los requisitos de ciudadano neogranadino. ${ }^{56}$

El general Joaquín Posada Gutiérrez señalaba que la constitución de 1843 establecía que para ejercer cargos públicos se necesitaba, además de la experiencia, el saber y la independencia, una honradez probada y añadía que para ser gobernador y prefecto era necesario poseer los derechos de ciudadanía y gozar de buen concepto público. ${ }^{57}$ Este mismo general, siendo gobernador de la provincia de Cartagena en 1847, recomendaba con especial cuidado a la asamblea electoral "no se llamen a servir a los destinos de jefes políticos y alcaldes, sino a personas conocidas por su amor al país, por su honradez, por su probidad y aptitudes". ${ }^{58}$

No obstante la sugerencia de éste, ese mismo año el jefe político del cantón de Remolino, José de la Peña, se vio envuelto en un lío jurídico con sus vecinos, al fugarse con una joven de 19 años. Los vecinos denunciaban que por este acto y por vivir en concubinato desde hacía muchos años con Juliana Navarro, de la Peña no podía ejercer ningún cargo público porque su conducta era inmoral. Los vecinos de Remolino preguntaban al gobernador:

\footnotetext{
${ }^{56}$ BLAA, Semanario de la Provincia de Cartagena, Cartagena, agosto 20 de 1843.

${ }^{57}$ Joaquín Posada, Memorias Histórico-Políticas, tomo IV, Bogotá, Imp. Nacional, 1929, p. 124.

${ }^{58}$ BLAA, Semanario de la Provincia de Cartagena, Cartagena, octubre 10 de 1847.
} 
¿Es posible que el primer invijilador de este cantón, de la observancia de las disposiciones legales, el hombre que jurara cumplir y hacer cumplir la constitución y las leyes, quebrante tan descaradamente ese juramento solemne, con actos que por su gravedad y trascendencia afectan fuertemente la moral y la vindicta pública?

El padre de la joven acudió con algunos vecinos al tribunal de justicia para denunciar al jefe político e impedir que éste siguiera desempeñando el cargo. Pero todo esto fue en vano ya que de la Peña lo siguió ejerciendo y fue nombrado diputado provincial, hecho que causó más indignación entre los vecinos de Remolino: "Triste es para nosotros manifestar que a pesar de muchos esfuerzos, a pesar de estar probados todos los delitos, José de la Peña, desempeñó la jefatura política hasta el dos de septiembre y la diputación a la cámara provincial y hoy mismo hiere con su presencia la vista de los honrados padres de familia y ofende desvergonzadamente el pudor del bello sexo de esta parroquia." ${ }^{59}$

Era una práctica de la época que los vecinos por medio de la prensa propusieran a algunos individuos para desempeñar los diferentes cargos públicos, rindiéndoles un reconocimiento a sus cualidades morales. Desde la prensa se llamaba la atención de los sufragantes, recomendándoles en quienes debían fijarse para votar por ellos, como lo hizo en 1849 el periódico El Porvenir:

Tengan presentes los electores que no es una cosa indiferente votar por esta o la otra persona sin tener más en cuenta que las simpatías personales, la mira de congraciarse con un acreedor....no, una función tan grande, un derecho tan sagrado, no debe cumplirse sino en bien de la Patria. Por tanto, es preciso que al votar conozcamos bien a las personas por quienes votamos y es preciso que sepamos de ellas que son patriotas, honrados, amigos del país, bastantes inteligentes... ${ }^{60}$

Ahora bien, como bien lo sostienen Carmagnani y Hernández, como la condición de buen vecino basado en el "modo honesto de vivir" no respondía a un ingreso, renta o salario capaz de ser cuantificado o monetarizado, sino que era de naturaleza subjetiva, al igual que las condiciones morales, recaía en manos de los comisionados (asamblea electoral, jefes políticos, gobernadores, alcaldes) la responsabilidad de calificar a partir de criterios cualitativos, fundados en valores consuetudinarios - como la honradez, el prestigio, el modo de razonar, la estima, los servicios prestados a la comunidad - si un habitante de la localidad debía ser

\footnotetext{
${ }^{59}$ BLAA, Semanario de la Provincia de Cartagena, Cartagena, enero 21 de 1847.

${ }^{60}$ BLAA, El Porvenir, Cartagena, junio 18 de 1849.
} 
considerado un buen vecino. ${ }^{61}$ Esto se convertía en un problema para decidir si una persona era honorable. Primero, porque aunque ciertas creencias, valores y nociones sean compartidos por todos los miembros de un sistema, cada grupo social produce una representación con matices propios y ella inspira en buena parte su comportamiento. ${ }^{62}$ Por ejemplo el "rapto de doncellas" podía escandalizar a las élites de una región más no a los estratos bajos de la misma. De igual forma, el concubinato, además de ser común, era visto como normal entre los sectores populares. Segundo, porque a lo largo del territorio neogranadino existían varias regiones que entendían de modo diferente lo que era ser una persona "honorable". No era lo mismo el recato bogotano al antioqueño o al costeño. Lo que escandalizaba al primero podía hacerlo en menor grado en el segundo. De este modo, la coexistencia de esta pluralidad de sociedades confirió a la condición de buen vecino una connotación distinta y particular a cada localidad.

Esta situación fue aprovechada, utilizada y manipulada por los partidos Liberal y Conservador, que removían de los cargos públicos a sus opositores manifestando no reunir las condiciones morales para desempeñarlo, como ocurrió en 1849 cuando asumió la presidencia de la República José Hilario López, quien por medio de sus agentes como gobernadores y jefes políticos, comenzó a sustituir de los cargos a los empleados de afinidad política conservadora. En noviembre de 1849, los vecinos de Soledad, (actual departamento del Atlántico) se quejaban ante el periódico El Porvenir por la injusta remoción que había sufrido el director del colegio de Santo Tomás, hecho que precipitó la renuncia del jefe político del cantón. Los vecinos manifestaban que la gobernación solicitó informes sobre la moralidad y buen desempeño de los directores de escuelas públicas oyéndolos previamente, para después escuchar a los cabildos respectivos, y del director de Santo Tomás, Manuel Álvarez, el cabildo informó que "en su concepto, el director era de conducta moral arreglada i que llenaba sus deberes completamente". Mientras tanto el jefe político, José Manuel Osorio, no contradijo el informe que se oyó en el cabildo y también elevó un informe al gobernador de la provincia, en los siguientes términos: "Nada desfavorable puedo decir a usted, respecto del director de la escuela del distrito de Santo Tomás, en quien la jefatura y cabildo

\footnotetext{
${ }^{61}$ M. Carmagnani y A. Hernández, "La ciudadanía orgánica mexicana”, p. 371-404.

${ }^{62}$ Sobre este tema ver. E. P. Thompson, "La economía moral de la multitud en la Inglaterra del siglo XVIII”, Costumbres en común, Barcelona, Crítica, 1995, p. 213-293.
} 
respectivo reconocen moralidad y una absoluta consagración en el desempeño de sus delicadas funciones".

Pese a los informes emitidos por el cabildo y el jefe político, el gobernador, desestimando a las autoridades de ese distrito declaró, fundado en el informe de algunos particulares, que Álvarez debía ser removido de su cargo porque la gobernación: "tiene informes de personas fidedignas referente a la conducta inmoral del director de la escuela de Santo Tomás”. Ante la posición asumida por el gobernador, los vecinos de Santo Tomás salieron en defensa de Álvarez y de Osorio. En una representación dirigida al gobernador le recordaban:

Señor gobernador Usted puede estimar cuanto quiera de sus dignos informantes, pero nosotros estimamos al Dr. Osorio más que a ellos, porque este es un verdadero patriota, honrado, joven de ilustración e influencia a quien no se le debiera sojuzgar en ningún caso, sino para motivos especiales y a nuestra vez estimamos como se merece y calificamos de peregrina, injusta y apasionada su resolución. ${ }^{63}$

\section{A modo de conclusión}

La continuidad de la vecindad en Nueva Granada durante la primera mitad del siglo XIX hizo más difícil el proceso de construcción del ciudadano moderno. Pese a los discursos modernizadores de las constituciones políticas neogranadinas, las comunidades seguían ancladas en un orden y en un imaginario tradicional y el ejemplo más palpable lo constituía el vecino, lo que mantenía la participación en los asuntos públicos dentro de los marcos de un orden corporativo y jerárquico. La Nueva Granada era una sociedad todavía enraizada en la crisálida del Antiguo Régimen, con un pasado histórico que no podía ser borrado y alterado de la noche a la mañana. Esta poseía sus propios tiempos y sus propios modos de entender el mundo. Unos y otros no siempre eran coincidentes con la ideología liberal. De esta forma, la permanencia de la vecindad demuestra que las sociedades no son unas arcillas que se pueden moldear de la manera que se quiera. ${ }^{64}$ Por más que la república supuso un cambio de régimen, este no pudo romper los lazos en que se habían ido concibiendo el ejercicio de la ciudadanía a partir del vecino.

\footnotetext{
${ }^{63}$ BLAA, El Porvenir, Cartagena, noviembre 25 de 1849.

${ }^{64}$ Juan Carlos Garavaglia, "El despliegue del Estado en Buenos Aires: de Rosas a Mitre”, Desarrollo Económico vol. 44, No. 175, Buenos Aires, 2004, p. 415-445.
} 
Así, durante a primera mitad del siglo XIX la cultura política que se instaura en la Nueva Granada tiene como elementos la tensión entre una concepción que bregaba por una administración vecinal de la comuna y aquella otra que aspiraba a imponer el modelo universal y abstracto de ciudadanía.

En definitiva, el estudio de la relación de la vecindad y la ciudadanía permite rastrear el imaginario, la cultura y la participación política en la Nueva Granada durante la primera mitad del siglo XIX. Lo que ha demostrado este artículo es que la vecindad era un elemento fundamental para considerar la representación de los individuos en una colectividad claramente establecida en la localidad. Muchas de las decisiones se tomaban conforme a la tradición local, a los intereses locales y a las diferentes estrategias de los individuos para acceder a la condición de ciudadano/vecino. En buena medida, este reconocimiento se daba sobre la base del buen comportamiento, limitado por la observancia de un vecindario del cual se forma parte y de cuya mirada dependía la reputación y el honor. ${ }^{65}$

${ }^{65}$ C. Aljovín, "Monarquía o República: ciudadano y vecino en Iberoamérica, 1750-1850”, p. 237; F. Núñez, “El concepto de vecino/ciudadano en Perú, 1750-1850”, p. 250. 